\title{
Atividade antibacteriana de plantas úteis e constituintes químicos da raiz de Copernicia prunifera
}

\author{
Mariane C. C. Ayres, ${ }^{1}$ Marcela S. Brandão, ${ }^{1}$ Gerardo M. Vieira-Júnior, ${ }^{1}$ Júlio César A. S. \\ Menor, ${ }^{2}$ Hildessandra B. Silva, ${ }^{2}$ Maria José S. Soares, ${ }^{2}$ Mariana H. Chaves ${ }^{* 1}$ \\ ${ }^{1}$ Departamento de Química, Centro de Ciências da Natureza, Universidade Federal do Piauí, 64049-550 \\ Teresina-PI, Brasil, \\ ${ }^{2}$ Departamento de Parasitologia e Microbiologia, Centro de Ciências da Saúde, Universidade Federal do Piauí, \\ 64049-550 Teresina-PI, Brasil
}

\begin{abstract}
RESUMO: Extratos etanólicos de Qualea grandiflora e Copernicia prunifera e extrato hexânico de Dipteryx lacunifera foram avaliados quanto a atividade antibacteriana, utilizando ensaios de difusão a partir de orifício e concentração inibitória mínima (CIM), frente a cepas Gram positivas e Gram-negativas, incluindo espécies multidroga resistentes. O extrato de $Q$. grandiflora apresentou atividade moderada para as cepas de Staphylococcus epidermidis (CIM $=500 \mu \mathrm{g}$ / $\mathrm{mL}$ ) e atividade fraca sobre as demais bactérias Gram-positivas testadas e inativo sobre bactérias Gram-negativas. Os resultados obtidos com S. epidermidis apesar de moderados são importantes, uma vez que este microorganismo é o principal causador de bacteremias e sepse associada com dispositivos médicos implantados. $\gamma$-Tocoferol e a mistura de sitosterol e estigmasterol foram isolados do extrato etanólico de raiz de $C$. prunifera e as estruturas destes compostos foram identificadas com base na análise dos dados espectrais de RMN e comparação com a literatura.
\end{abstract}

Unitermos: Qualea grandiflora, Copernicia prunifera, Dipteryx lacunifera, atividade antibacteriana, isoprenóides.

\begin{abstract}
Antibacterial activity of useful plants and chemical constituents of the roots of Copernicia prunifera". Ethanol extracts of Qualea grandiflora and Copernicia prunifera and hexane extract of Dipteryx lacunifera were evaluated by diffusion in agar and minimum inhibitory concentration (MIC) against Gram-positive and Gram-negative bacteria including multiresistant drug strains. The extract of $Q$. grandiflora presented moderate activity for Staphylococcus epidermidis (MIC $=500 \mu \mathrm{g} / \mathrm{mL}$ ) and weak activity against other Gram-positive strains and inactive for Gram-negative species. The results obtained for S. epidermidis despite being moderate are important because this pathogen is often recovered from bacteremia and sepsis from infections of implanted devices. $\gamma$-Tocopherol and the mixture of sitosterol and stigmasterol were isolated from the ethanol extract of the roots of $C$. prunifera. The structures of these compounds were identified by NMR spectroscopy and comparison with literature data.
\end{abstract}

Keywords: Qualea grandiflora, Copernicia prunifera, Dipteryx lacunifera, antibacterial activity, isoprenoids.

\section{INTRODUÇ̃̃O}

As doenças infecciosas continuam a ocupar posição de destaque como causa de morbidade e mortalidade em todo o mundo, apesar dos avanços técnico-científicos. Um dos principais fatores que explicam essa liderança é a capacidade que os microrganismos possuem para a aquisição de mecanismos de resistência aos antimicrobianos (Silver \& Bostian, 1993). Tal habilidade impõe a necessidade permanente de pesquisas e desenvolvimento de novas drogas a serem utilizadas no combate e/ou controle dos microrganismos (Rates, 2001; Cragg et al., 1997; Cowan, 1999; Packer \& Luz, 2007).
A busca de substâncias com atividades antimicrobianas tem direcionado a atenção sobre os produtos naturais e, entre estes, os derivados das plantas superiores têm, nos últimos anos, despertado a investigação para o potencial da flora brasileira (Almeida et al., 1998; Alves et al., 2000; Rates, 2001; Suffredini et al., 2004; Michelin et al., 2005; Lima et al., 2006).

$\mathrm{O}$ presente artigo relata os resultados da avaliação da ação antibacteriana de extratos de raiz de Copernicia prunifera Mart., folha de Qualea grandiflora Mart., casca do fruto de Dipteryx lacunifera Ducke e o isolamento e identificação do $\gamma$-tocoferol (1) e de uma mistura de sitosterol (2) e estigmasterol (3) da fase acetato de etila do extrato etanólico das raízes da $C$. 
prunifera.

Q. grandiflora é uma Vochysiaceae, típica do cerrado, conhecida com o nome comum de pau-terra-dafolha-grande, pau-terra-do-cerrado e ariavá. A infusão dos frutos é usada no tratamento de asma (Corrêa, 1974) e a infusão das cascas para limpeza externa de úlceras e feridas, e também contra inflamações (Almeida et al., 1998).

C. prunifera (Arecaceae), sinonímia C. cerifera, é conhecida comumente como carnaúba. As folhas desta espécie acumulam uma cera constituída basicamente de ésteres, álcoois e ácidos graxos de massa molecular alta. A cera é utilizada na fabricação de cosméticos e produtos de limpeza, filmes plásticos e fotográficos. É usada ainda, na composição de revestimentos, impermeabilizantes, lubrificantes, vernizes, papelcarbono, dentre outros (http://www.pvp.com.br). A raiz da carnaúba é popularmente utilizada na forma de elixir, para o tratamento de sífilis e afecções cutâneas (Carvalho, 1957; Agra et al., 2007). Segundo Sousa et al., (2007) o extrato etanólico da raiz apresenta um baixo conteúdo de compostos fenólicos e baixa atividade antioxidante, quando comparado a outras espécies.

Dipteryx lacunifera Ducke, sinonímia Coumarouna lacunifera, é uma LeguminosaePapilionoideae, conhecida popularmente como castanha de burro e garampara, sendo encontrada na região meionorte do Brasil (Maranhão e Piauí) (http://www.ildis. org/LegumeWeb). Esta espécie produz um fruto, cuja amêndoa é comestível, comercializado em feiras livres do município de Bom Jesus-PI, com o nome de fava de morcego. Em trabalho anterior, Mendes \& Silveira (1994), relataram a composição de ácidos graxos das amêndoas e o isolamento de $\beta$-farneseno e dois diterpenos furanocassanos, nos frutos desta espécie. Recentemente Vieira Júnior et al. (2007) relataram o isolamento do ácido vinhaticóico, $\beta$-farneseno e espatulenol do extrato hexânico e a ocorrência de $\alpha$-copaeno, $\beta$-elemeno, trans-cariofileno, $\quad \beta$-farneseno, $\quad$ germacreno-D, biciclogermacreno, $\gamma$-cadineno, espatulenol e óxido de cariofileno no óleo essencial, ambos obtidos das cascas do fruto da D. lacunifera.

\section{MATERIAL E MÉTODOS}

\section{Métodos gerais}

As separações cromatográficas em coluna à pressão atmosférica, foram realizadas em gel de sílica 60 (0,063-0,20 mm) da Merck e Sephadex LH-20 da Sigma. As placas para cromatografia em camada delgada comparativa (CCDC) foram preparadas com $0,25 \mathrm{~mm}$ de espessura, usando como fase estacionária, gel de sílica $60 \mathrm{GF}_{254}$ da Merck e $60 \mathrm{G}$ Vetec. As revelações das cromatoplacas foram feitas por borrifamento com solução de sulfato cérico. Os espectros de ressonância magnética nuclear (RMN) foram obtidos em espectrômetro Brüker,

modelo Avance DRX-500, operando a $500 \mathrm{MHz}$ na freqüência do hidrogênio e a $125 \mathrm{MHz}$ na freqüência do carbono-13. O sinal residual do solvente ou do TMS foi usado como referência interna. O solvente utilizado na dissolução das amostras para obtenção dos espectros foi o clorofórmio deuterado $\left(\mathrm{CDCl}_{3}\right.$, Isotec - INC).

\section{Material vegetal}

Folhas de Q. grandiflora (TEPB 10091) foram coletadas no município de Demerval Lobão-PI em abril de 2002, raízes de carnaúba no município de Campo Maior - PI, em janeiro de 2004 e frutos de D. lacunifera (TEPB 18.246) no município de Bom Jesus-PI, em agosto de 2003. O material vegetal foi identificado pela Dra. Gardene Maria de Sousa e Dr. Haroldo Cavalcante de Lima. Todas as exsicatas encontram-se depositadas no Herbário Graziela Barroso da UFPI.

\section{Preparação dos extratos}

O material vegetal das espécies $Q$. grandiflora e $C$. prunifera foi seco à temperatura ambiente e moído em moinho de facas. Os extratos foram preparados por maceração com etanol à temperatura ambiente por quatro vezes consecutivas e cada extração tinha a duração de quatro dias. Os extratos foram reunidos, concentrados em evaporador rotativo e liofilizados em liofilizador E-C MicroModulyo acoplado a bomba de vácuo valuPump VLP80 Savant. Os frutos secos da D. lacunifera foram separados em cascas e sementes, as cascas foram submetidas à lavagem com hexano à temperatura ambiente, para retirar o excesso de óleo e posteriormente foram moídas e extraídas por maceração com hexano. Após concentração o extrato hexânico total, incluindo o obtido da lavagem, foi mantido em dessecador sob vácuo, até peso constante. $\mathrm{O}$ rendimento dos extratos foi calculado pela expressão: Rendimento $(\%)=($ massa do extrato/massa do material vegetal) $\mathrm{x}$ 100 .

\section{Fracionamento do extrato etanólico da raiz de $C$. prunifera}

O extrato etanólico de $C$. prunifera $(30 \mathrm{~g})$ foi submetido a partição com acetato de etila e $\mathrm{MeOH}-\mathrm{H}_{2} \mathrm{O}$ (1:2), resultando nas fases: aquosa, AcOEt $(4,6 \mathrm{~g}) \mathrm{e}$ interfase (1,3 g). A fase AcOEt foi fracionada em coluna de gel de sílica, eluída com hexano-AcOEt, em ordem crescente de polaridade, resultando em 50 frações. A fração M-9 (290 mg), eluída com hexano-AcOEt (95:5), foi recromatografada em coluna de Sephadex LH-20 eluída com hexano-diclorometano (1:4), resultando na substância 1 (83 mg). A fração M17 (215 mg), eluída com hexano-AcOEt $(9: 1)$ foi dissolvida parcialmente em $\mathrm{MeOH}$ à temperatura ambiente, posteriormente aquecida em banho Maria até a dissolução máxima e 
filtrada. O sobrenadante permaneceu em repouso para a formação dos cristais, que depois de separados por filtração forneceu a mistura de 2 e 3 (25 mg).

\section{Cepas microbianas}

Os testes de atividade antibacteriana foram realizados com as seguintes cepas padrão: Escherichia coli ATCC 25922, Escherichia coli ATCC 35218; Klebsiella pneumoniae ATCC 700603, Pseudomonas aeruginosa ATCC 27853, Staphylococcus aureus ATCC 25923, Staphylococcus epidermidis ATCC 12228 e Enterococcus faecalis ATCC 29212. Também foram avaliadas as seguintes cepas obtidas de origem clínica: Stenotrophomonas maltophilia EM 012004, Staphylococcus aureus resistentes à meticilina MRSA PI-98 (cepa pertencente ao Clone Epidêmico Brasileiro; Soares et al., 2000), Staphylococcus epidermidis MRSE H-111 e Enterococcus faecalis 7426 (cepa resistente à vancomicina e que contém o gene van A; Soares et al., 2000). Todas as cepas foram obtidas a partir de culturas estoque, que são mantidas no Laboratório de Microbiologia da UFPI. Estas, inicialmente, conservadas sob condições de congelamento, foram submetidas a testes bioquímicos específicos para a confirmação da pureza e identificação da espécie, através de procedimentos recomendados por Konemam et al.(1999).

\section{Técnica de difusão em meio sólido a partir de orifício}

O perfil de susceptibilidade aos produtos vegetais foi investigado, inicialmente, através do teste de difusão dos extratos vegetais em meio sólido, a partir de orifício como descrito por Alves et al. (2000), com algumas modificações e observando as recomendações do NCCLS/CLSI (2005a). As suspensões bacterianas, cultivadas em caldo Mueller-Hinton (Difco) por 24 horas a $35{ }^{\circ} \mathrm{C}$ em estufa bacteriológica, foram padronizadas em solução salina estéril $(0,9 \%)$ para uma concentração de $10^{8} \mathrm{UFC} / \mathrm{mL}$ (unidades formadoras de colônias), utilizando a escala 0.5 de McFarland e, em seguida, foram semeadas com o auxílio de swab estéril, sobre as superfícies de placas de Petri, contendo Ágar MuellerHinton (Difco). Decorrido 10 minutos para a secagem dos inóculos bacterianos, foram feitos três orifícios de 6 $\mathrm{mm}$ de diâmetro, com auxílio de um molde e de sucção com bomba de vácuo, e estes foram preenchidos com $120 \mu \mathrm{L}$ dos extratos vegetais, nas concentrações de $10 \mathrm{e}$ $50 \mathrm{mg} / \mathrm{mL}$ em dimetil sulfóxido (DMSO; Vetec) a $50 \%$. O terceiro orifício foi preenchido com o DMSO, sendo este utilizado como controle negativo.

Os resultados da susceptibilidade aos produtos vegetais foram expressos em termos de tamanho de diâmetro do halo de inibição do crescimento microbiano, arbitrariamente, padronizado e considerado na maior concentração utilizada como: menor que $9 \mathrm{~mm}$ não ativo; 9-14 mm, parcialmente ativo; maior que 14 a 17 $\mathrm{mm}$, ativo e maior que $17 \mathrm{~mm}$, muito ativo. Cada teste foi realizado em triplicata.

Paralelamente, placas de ágar MuellerHinton contendo discos de antimicrobianos (oxacilina, vancomicina, sulfametoxazol-trimetoprim, quinupristina+dalfopristina e imipenem) utilizados na verificação da susceptibilidade para terapêutica, foram empregadas para monitorar a estabilidade gênica das espécies bacterianas avaliadas e para fornecer comparações da eficiência ou não dos produtos vegetais pesquisados. O tamanho dos halos de inibição utilizados como padrão foram os recomendados pelo NCCLS/ CLSI (2005b). Os discos dos antimicrobianos foram obtidos da empresa CECON.

\section{Técnica de microdiluição em caldo para a determinação da concentração inibitória mínima (CIM)}

Os extratos vegetais que apresentaram atividade antimicrobiana para a maioria das cepas microbianas e halos de inibição iguais ou maiores que $9 \mathrm{~mm}$ foram submetidos ao teste de microdiluição em caldo para a determinação da concentração inibitória mínima (CIM). Este ensaio foi realizado em microplacas estéreis de 96 cavidades (INLAB) com fundo em forma de "U". Um volume de $200 \mu \mathrm{L}$ dos diversos extratos vegetais, preparados na concentração de $2000 \mu \mathrm{g} / \mathrm{mL}$, empregando-se DMSO a 10\%, foram filtrados utilizando filtros milipore $0,45 \mu \mathrm{m}$ e em seguida inoculados nas colunas de 1 a 9 da linha A. Os demais orifícios foram preenchidos com $100 \mu \mathrm{L}$ de caldo Mueller-Hinton (duas vezes concentrado). Em seguida, uma alíquota de $100 \mu \mathrm{L}$ do conteúdo de cada orifício da linha $\mathrm{A}$ foi transferido para os orifícios da linha B, e após homogeneização, o mesmo volume foi transferido para a linha $\mathrm{C}$, repetindose este procedimento até a linha $\mathrm{H}$, e desprezando-se após homogeneização o excesso da diluição, obtendose assim concentrações decrescentes dos extratos (1000 $\mu \mathrm{g} / \mathrm{mL}$-linha B; $500 \mu \mathrm{g} / \mathrm{mL}-$ linha $\mathrm{C} ; 250 \mu \mathrm{g} / \mathrm{mL}-$ Linha $\mathrm{D}$, e assim por diante) Os inóculos microbianos na concentração de 0,5 de McFarland $\left(10^{8} \mathrm{UFC} / \mathrm{mL}\right)$ foram diluídos $1 / 10$ em solução salina estéril $(0,9 \%)$ e desta diluição um volume de $5 \mu \mathrm{L}\left(10^{4} \mathrm{UFC} / \mathrm{mL}\right)$ foram depositadas em todos os orifícios das linhas A-H. Os orifícios das colunas 10, 11 e 12 foram destinados para os testes de controle do experimento. Os orifícios da coluna 10 foram reservados para o controle negativo da atividade inibitória do diluente DMSO, utilizado na preparação dos extratos. Nesta coluna, a solução de DMSO a $10 \%$ foi diluída em caldo Mueller-Hinton até a linha $\mathrm{H}$ e o mesmo inóculo microbiano foi acrescido. Os orifícios da coluna 11 receberam apenas caldo MuellerHinton e o inóculo microbiano, possibilitando o controle positivo da viabilidade bacteriana e os orifícios da 
coluna 12 receberam apenas caldo Mueller-Hinton para a verificação da esterilidade da placa. As microplacas foram incubadas em estufa bacteriológica a $35^{\circ} \mathrm{C}$ por 18 horas. Decorrido este intervalo de tempo foi acrescido a cada um dos orifícios $20 \mu \mathrm{L}$ de uma solução aquosa de TTC (cloreto de trifenil tetrazolium; VETEC) a $0,5 \%$ e as microplacas foram novamente re-incubadas por mais três horas a $35^{\circ} \mathrm{C}$. Após esta última incubação a presença de uma coloração vermelha nos orifícios era interpretada como prova negativa do efeito inibitório do extrato, enquanto a ausência da coloração vermelha era considerada prova positiva da ação inibitória do extrato. ACIM foi definida como a menor concentração do extrato em $\mu \mathrm{g} / \mathrm{mL}$ capaz de impedir o crescimento microbiano (ou seja o aparecimento da coloração vermelha). Cada teste foi realizado em sextuplicata. Neste teste, foi acrescentada também a cepa de $S$. aureus ATCC 29213, uma vez que esta é usada para este tipo de avaliação, conforme recomenda o NCCLS/CLSI (2005a).

\section{RESULTADOS E DISCUSSÃO}

Os extratos etanólicos de folhas de $Q$. gradiflora e de raiz de $C$. prunifera e o extrato hexânico de cascas do fruto de $D$. lacunifera foram obtidos com rendimento de 9,$8 ; 4,6$ e $7 \%$ respectivamente.

O fracionamento, através de cromatografia em coluna de gel de sílica, da fase acetato de etila da partição do extrato etanólico das raízes de carnaúba resultou no isolamento e identificação do $\gamma$-tocoferol (1) e da mistura de sitosterol (2) e estigmasterol (3), inéditas na espécie.

$\mathrm{O}$ espectro RMN ${ }^{1} \mathrm{H}$ de $\mathbf{1}$ apresentou sinais característicos de tocoferol: dois sinpletos em $\delta 2,15$ e 2,13, atribuídos a metilas $\left(\mathrm{CH}_{3}\right)$ ligadas ao anel aromático; um tripleto em $\delta 2,68(J=6,7 \mathrm{~Hz}, 2 \mathrm{H})$, correspondente aos hidrogênios ligados ao carbono metilênico, C-4 e um sinpleto em $\delta 6,38$, atribuído ao H-5 do anel aromático.

$\mathrm{O}$ espectro $\mathrm{RMN}{ }^{13} \mathrm{C}-\mathrm{BB}{ }^{1} \mathrm{HD}$ apresentou 28 sinais, que através da análise do espectro DEPT $135^{\circ}$ permitiu definir a presença de 7 sinais referentes a carbonos metílicos $\left(\mathrm{CH}_{3}\right), 11$ a metilênicos $\left(\mathrm{CH}_{2}\right)$, 4 a metínicos $(\mathrm{CH})$ e 6 a carbonos não hidrogenados; revelando uma fórmula molecular $\mathrm{C}_{28} \mathrm{H}_{48} \mathrm{O}_{2}$ e um índice de deficiência de hidrogênio (IDH) igual a 5, compatível com a presença de 2 anéis, sendo um deles aromático. A comparação dos dados de RMN observados com os relatados na literatura por Matsuno e Urano (1976) permitiu identificar o $\gamma$-tocoferol (1).

As substâncias $\mathbf{2}$ e $\mathbf{3}$ apresentaram-se como uma mistura de difícil separação. A análise desta fração por cromatografia em camada delgada de gel de sílica, eluída com hexano-AcOEt (8:2) e revelada com solução de sulfato cérico, mostrou uma mancha de coloração rosa que se tornou azul após algum tempo de aquecimento.

$\mathrm{O}$ espectro RMN ${ }^{1} \mathrm{H}$ da mistura de $\mathbf{2}$ e $\mathbf{3}$ apresentou sinais que caracterizam mistura de esteróis $\Delta^{5}$ : multipleto em $\delta 3,52$, atribuível ao hidrogênio do carbono carbinólico C-3 e um sinpleto largo em $\delta$ 5,3 , atribuível ao hidrogênio oleofínico ligado a C-6. Observou-se ainda dois sinais entre $\delta 4,1$ e 5,2, que foram atribuídos aos hidrogênios olefínicos H-22 e H-23 da substância 3.

O espectro RMN ${ }^{13} \mathrm{C}-\mathrm{BB}{ }^{1} \mathrm{HD}$ de 2 e 3 apresentou 29 sinais mais intensos; entre os quais, dois sinais em $\delta 141,0$ e 121,9 referentes aos carbonos olefínicos C-5 e C-6, respectivamente nos dois esteróides. Os sinais com menor intensidade, em $\delta$ 138,5 e 129,6 atribuíveis a C-22 e C-23 respectivamente confirmaram a presença da substância 3 na mistura de esteróides. A análise dos dados observados e a comparação com os reportados na literatura (De-Eknamkul \& Potduang, 2003) possibilitou a identificação dos esteróides sitosterol (2) e estigmasterol (3), na proporção de 64:36, determinada pela comparação da integração dos sinais dos hidrogênios carbinólicos (H-3) e olefínicos (H-22 ou $\mathrm{H}-23)$ do espectro de RMN ${ }^{1} \mathrm{H}$.

$\mathrm{Na}$ Tabela 1, encontram-se expressos os resultados obtidos para os ensaios das atividades antibacterianas dos extratos vegetais estudados, pela técnica da difusão em meio sólido, a partir do orifício e microdiluição em caldo. Esta última técnica avaliou a concentração inibitória mínima (CIM).

O ensaio de difusão em meio sólido a partir de orifício foi utilizado como triagem inicial da avaliação do potencial antibacteriano dos extratos pesquisados, sendo este empregado por vários autores como metodologia mais apropriada que o teste de difusão do extrato a partir de disco (Brantner et al., 1994; Alves et al., 2000; Essawi \& Srour, 2000).

Através dos resultados obtidos, verificou-se que o extrato etanólico das folhas de $Q$. grandiflora, apresentou especialmente atividade inibitória classificada como moderada ou ativa sobre o crescimento microbiano, para as espécies Gram-positivas e para a bactéria $S$ maltophilia. Estes resultados pareceram bastante promissores, especialmente para as bactérias Grampositivas, uma vez que este extrato apresentou um efeito inibidor tanto sobre as cepas das espécies mais sensíveis como sobre as mais resistentes. Por exemplo, a cepa de $S$. aureus MRSA PI-98 e a cepa de $S$. epidermidis MRSE H-111 são multidrogas-resistentes, sendo sensíveis apenas a vancomicina, antimicrobiano que apresenta significativa toxidade e exige monitoramento médico em sua administração (Marangoni, 1997; Soares et al., 2000).

No final de 1999, antes da introdução dos antimicrobianos quinupristina + dalfopristina e do linezolida, cepas de Enterococcus sp. semelhantes à cepa de $E$. faecalis 7426 , que é resistente a vancomicina, tornava as infecções causadas por cepas com esse perfil de susceptibilidade praticamente "intratáveis" (Marangoni, 1997). Contudo, infelizmente, já 
começaram a surgir cepas de Enterococcus sp resistentes a estes antimicrobianos, fato bastante preocupante para a saúde pública (Gonzales et al., 2001). Assim, as observações sobre a atividade antibacteriana do extrato de Q. grandiflora, parecem demonstrar que os diferentes mecanismos de resistência que estas cepas possuem, não estão oferecendo nenhuma proteção contra o (s) componente(s) ativo(s) presentes neste extrato.

A baixa ou mesmo ausente atividade inibitória do extrato etanólico de Q. grandiflora, sobre as bactérias Gram-negativas (em especial E. coli, e K. pneumoniae), talvez esteja relacionada com as diferenças estruturais que estas bactérias apresentam em relação às Grampositivas (presença de uma membrana externa sobre o peptideoglicano, presença de cápsula, porinas; Koneman et al., 1999) que podem estar dificultando a ação dos componentes bioativos dos produtos vegetais investigados. Outra suposição para esta resistência pode ser em função das substâncias potencialmente ativas estarem presentes em concentrações muito baixas, ou mesmo que estes extratos não apresentem nenhum metabólito ativo sobre estas bactérias. A cepa de $S$. maltophilia apesar de ser também um microrganismo Gram-negativo, apresenta estrutura e metabolismo bastante diferente das bactérias Gram-negativas anteriormente referidas (Koneman, et al., 1999), o que pode talvez explicar a acentuada atividade inibitória do extrato de $Q$. grandiflora. Destaca-se, ainda, que a atividade deste extrato sobre esta espécie bacteriana sugeriu ser bastante promissora, principalmente se for avaliado que a bactéria em questão apresenta poucas possibilidades terapêuticas como, por exemplo, sulfametoxazol-trimetoprima e algumas cepas desta espécie respondem a ceftazidima, as fluoroquinas ou minociclinas. Contudo, a cepa testada ( $S$. maltophilia EM 0104) só é sensível a sulfametoxazol-trimetoprima.

De um modo geral os extratos de D. lacunifera e C. prunifera apresentaram-se apenas parcialmente ativos (halos de inibição de 9-14 mm) ou não apresentaram atividade significativa (halos menores que $9 \mathrm{~mm}$ ) para todas as bactérias avaliadas.

Neste estudo, considerou-se que o extrato etanólico de Q. grandiflora possuía algum grau de

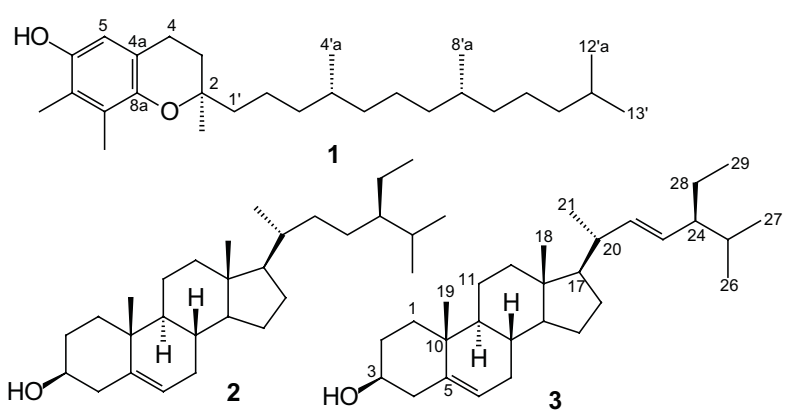

Figura 1. Estruturas das substâncias $\gamma$-tocoferol (1), sitosterol (2) e estigmasterol (3) isoladas do extrato etanólico da raiz de C. prunifera. atividade inibitória porque o tamanho dos halos de inibição apresentados eram semelhantes ou até mesmo maiores que os halos padrão de antimicrobianos que são utilizados na terapêutica, e que foram empregados como controle nos experimentos, como por exemplo, $15 \mathrm{~mm}$ ou mais para vancomicina, ou $13 \mathrm{~mm}$ ou mais para oxacilina (NCCLS/CLSI (2005b). Esta proposição tem sido adotada por diversos pesquisadores para que se possa indicar qual espécie vegetal deve passar para a etapa seguinte, que seria determinar o valor da concentração inibitória mínima (CIM) (Essawi \& Srour, 2000; Brantner et al., 1994; Alves et al., 2000). A determinação da CIM é um método acurado para que se possa direcionar a purificação e o isolamento químico dos componentes vegetais que sejam responsáveis pela atividade antibacteriana observada em ensaios preliminares (Salvat et al., 2001; Tanaka et al., 2005; Dall'Angol et al., 2003; Fabry et al., 1998).

$\mathrm{Na}$ Tabela 1 estão apresentados os resultados obtidos para a determinação da CIM do extrato etanólico de $Q$. grandiflora frente às espécies bacterianas Grampositivas e Gram-negativas. Os demais extratos vegetais não foram avaliados neste ensaio, uma vez que apresentaram somente atividade moderada sobre bactérias Gram-positivas no teste de difusão em meio sólido a partir de orifício.

De um modo geral, o extrato etanólico de $Q$. grandiflora apresentou para as bactérias Gram-negativas CIM maiores que $1000 \mu \mathrm{g} / \mathrm{mL}$; enquanto que para as espécies Gram-positivas, variou de $500 \mu \mathrm{g} / \mathrm{mL}$ para as cepas de $S$. epidermidis, $1000 \mu \mathrm{g} / \mathrm{mL}$ para as cepas de $S$. aureus e E. faecalis ATCC 29212 e maior que 1000 $\mu \mathrm{g} / \mathrm{mL}$ para cepa de E. faecalis portadora do gene vanA (Tabela 1).

Extratos de plantas são considerados com bom potencial inibitório se demonstram atividade em concentrações de até $100 \mu \mathrm{g} / \mathrm{mL}$, atividade inibitória moderada de $100-500 \mu \mathrm{g} / \mathrm{mL}$, atividade fraca de $500-1000 \mu \mathrm{g} / \mathrm{mL}$ e inativos maiores que $1000 \mu \mathrm{g} / \mathrm{mL}$ (Dall' Angol et al., 2003; Fabry et al., 1998; Tanaka et al., 2005). Portanto, de acordo com este padrão estabelecido o extrato etanólico de $Q$. grandiflora não apresentou atividade sobre as espécies Gram-negativas e sobre a cepa de E. faecalis 7426. Para as demais espécies Grampositivas, apresentou atividade inibitória moderada (500 $\mu \mathrm{g} / \mathrm{mL}$ ) para as cepas de $S$. epidermidis (ATCC 12228 e H111) e uma atividade inibitória fraca para todas as cepas de $S$. aureus e para E. faecalis ATCC 29212.

Sabe-se que a constituição química de um extrato é decorrente dos métodos e reagentes químicos utilizados para a sua obtenção, que geralmente os componentes ativos se encontram em baixas concentrações e num extrato bruto estes podem estar mais diluídos (Cechinel Filho \& Yunes, 1998; Rates, 2001). Avaliando esta constatação e verificando que a literatura relata propriedades antimicrobianas para espécies da família Vochysiaceae (Suffredini et al., 2004; 


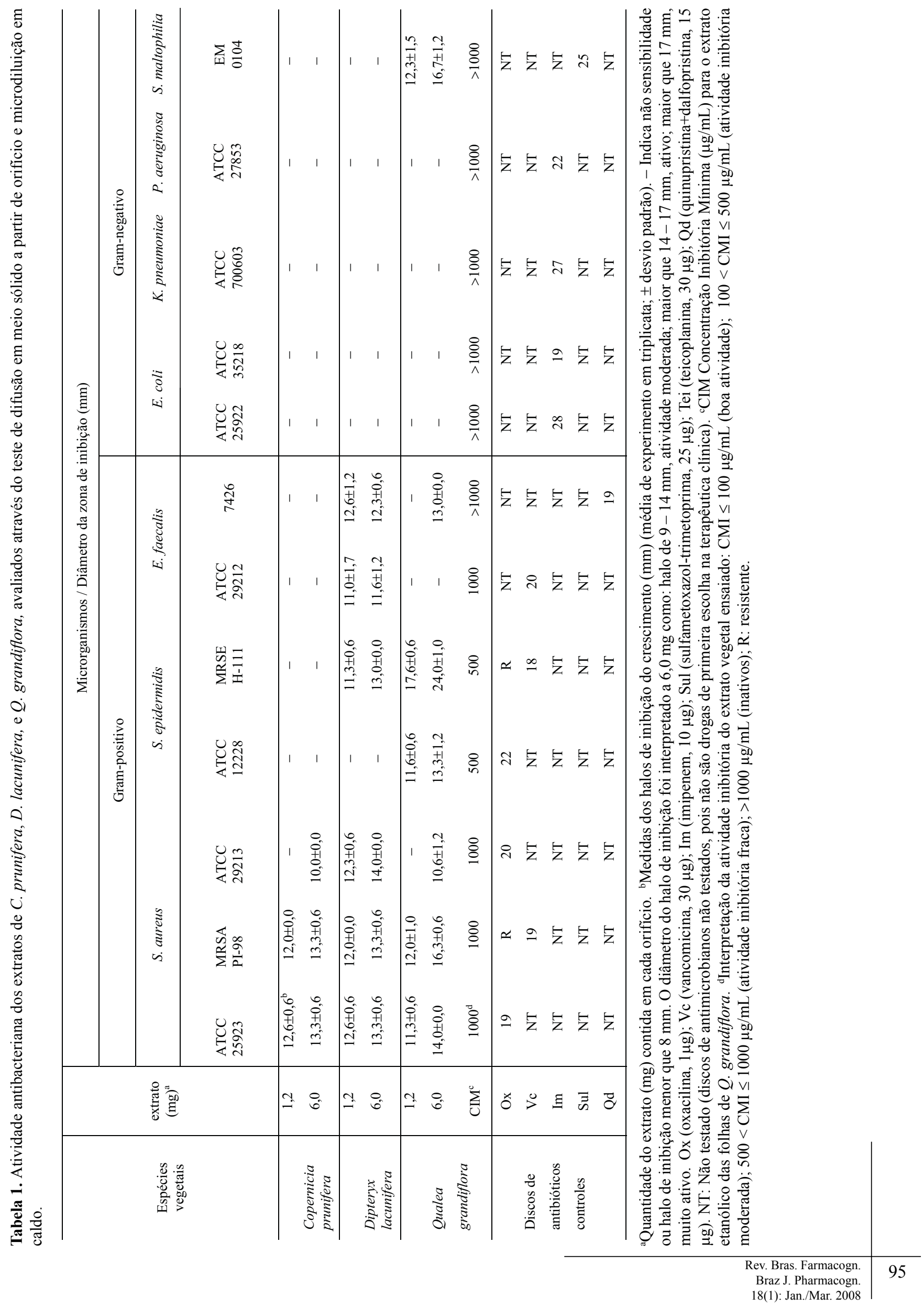


Hess et al., 1995), na qual o gênero Qualea, se encontra classificado, a descrição da presença de triterpenos na espécie Vochysia pacifica, que sabidamente apresentam atividade antimicrobiana (Weninger et al., 2005) e, por fim, a atividade inibitória moderada sobre as cepas de Staphylococcus epidermidis, importante patógeno relacionado com a ocorrência de endocardites, bacteremias, sepse, bem como outras graves infecções envolvidas com dispositivos médicos implantados tais como cateteres e próteses (Konemann et al., 1999; Marangoni, 1997), estimulam a continuar o estudo das frações deste extrato, na perspectiva de que se possa revelar uma possível ação antimicrobiana pelo menos para este coco Gram-positivo.

\section{AGRADECIMENTOS}

Os autores agradecem ao Dr. Haroldo Cavalcante de Lima do Instituto de Pesquisa Jardim Botânico do Rio de Janeiro e Dra. Gardene Maria de Sousa do Departamento de Biologia da Universidade Federal do Piauí, pela identificação do material botânico, aos órgãos de fomento pelas bolsas concedidas a Gerardo M. Vieira Jr.; Mariane C.C. Ayres e Mariana H. Chaves (CNPq) e Marcela S. Brandão (UFPI) e pelo apoio financeiro (CNPq, CAPES/PROCAD e FINEP, FAPEPI), ao Centro Nordestino de Aplicação e Uso da Ressonância Magnética Nuclear (CENAUREMN) da UFC pela obtenção dos espectros de RMN.

\section{REFERÊNCIAS}

Agra MF, França PF, Barbosa-Filho JM 2007. Synopsis of the plants known as medicinal and poisonous in Northeast of Brazil. Rev Bras Farmacogn 17: 114-140.

Almeida SP, Proença CEB, Sano SM, Ribeiro JF 1998. Cerrado Espécies Vegetais Úteis. Planatina: Embrapa.

Alves TMA, Silva AF, Brandão M, Grandi TSM, Smânia EFA, Smânia Junior A, Zani CL 2000. Biological screening of Brazilian medicinal plants. Mem I Oswaldo Cruz 95: 367-373.

Brantner A, Pfeiffer H, Brantner H 1994. Applicability of diffusion methods required by the pharmocopoeias for testing antibacterial activity of natural compounds. Pharmazie 49: 512-516.

Carvalho JBM 1957. Ensaios sobre a Carnaubeira. Rio de Janeiro: Ministério da Agricultura.

Cechinel Filho V, Yunes RA 1998. Estratégias para a obtenção de compostos farmacologicamente ativos a partir de plantas medicinais: Conceitos sobre modificação estrutural para a otimização da atividade. Quim Nova 21: 99-105.

Corrêa MP 1974. Dicionário de Plantas Úteis do Brasil, Rio de Janeiro: Imprensa Nacional, v. 5.

Cowan MM 1999. Plant products as antimicrobial agents. Clin Microbiol Rev 12: 564-582.
Cragg GM, Newman DJ, Snader KM 1997. Natural products in drug discovery and development. J Nat Prod 60: 52-60.

Dall' Agnol R, Ferraz A, Bernardi AP, Albring D, Nör C, Sarmento L, Lamb L, Hass M, von Poser G, Schapoval EES 2003. Antimicrobial activity of some Hypericum species. Phytomedicine 10: 511-516.

De-Eknamkul W, Potduang B 2003. Biosynthesis of $\beta$-sitosterol and stigmasterol in Croton sublyratus proceeds via a mixed origin of isoprene units. Phytochemistry 62: 389-398.

Essawi T, Srour MJ 2000. Screening of some Palestinian medicinal plants for antibacterial activity. $J$ Ethnopharmacol 70: 343-349.

Fabry W, Okemo PO, Ansorg R 1998. Antibacterial activity of East African medicinal plants. J Ethnopharmacol 60: 79-84.

Gonzales RD, Schreckenberger PC, Graham MB, Kelkar S, DenBesten K, Quinn JP 2001. Infections due to vancomycin-resistant Enterococcus faecium resistant to linezolid. Lancet 357: 1179.

Hess SC, Brum RL, Honda NK, Cruz AB, Moretto E, Cruz RB, Messana I, Ferrari F, Cechinel Filho V, Yunes RA 1995. Antibacterial activity and phytochemical analysis of Vochysia divergens (Vochysiaceae). $J$ Ethnopharmacol 42: 97-100.

http://www.ildis.org/LegumeWeb, acessada em agosto de 2006.

http://www.pvp.com.br, acessada em junho de 2005.

Koneman EW, Allen SE, Janda WM, Schreckenberger PD, Winn WC 1999. Diagnóstico Microbiológico Texto y Atlas Color. 5. ed. Buenos Ayres: Panamericana.

Lima MRF, Ximenes CPA, Luna JS, Sant'Ana AEG 2006. The antibiotic activity of some Brazilian medicinal plants. Rev Bras Farmacogn 16: 300-306.

Marangoni DV 1997. Staphylococcus aureus. In: Rodrigues EAC, Mendonça JS, Amarante JMB, Alves Filho MB, Grinbaum RS, Richtmann R (eds). Infecções Hospitalares Prevenção e Controle. São Paulo: Sarvier, p.573-591.

Matsuno M, Urano S 1976. ${ }^{13} \mathrm{C}$ NMR spectra of tocopherols and 2,2-dimethylchromanols. Tetrahedron 32: 229-231.

Mendes FNP, Silveira ER 1994. Fatty acids, sesqui- and diterpenoids from seed of Dipteryx lacunifera Phytochemistry 35: 1499-1503.

Michelin DC, Moreschi PE, Lima AC, Nascimento GGF, Paganelli MO, Chaud MV 2005. Avaliação da atividade antimicrobiana de extratos vegetais. Rev Bras Farmacogn 15: 316-320.

National Committee for Clinical Laboratory Standards 2005a. Performance standards for antimicrobial susceptibility testing. Information supplement 15 th M100-S15. Wayne. PA: NCCLS/CLSI, 2005/CLSI.

National Committee for Laboratory Standards $2005 \mathrm{~b}$. Performance standards for antimicrobial disk susceptible test: Approved standard M2-A8. Wayne. 
PA: NCCLS/CLSI, 2005/CLSI.

Packer JF, Luz MMS 2007. Método para avaliação e pesquisa da atividade antimicrobiana de produtos de origem natural. Rev Bras Farmacogn 17: 102-107.

Rates SMK 2001. Plants as source of drugs. Toxicon 39: 603-613.

Salvat A, Antonacci L, Fortunato RH, Suarez EY, Godoy HM 2001. Screening of some plants from northern Argentina for their antimicrobial activity. Lett Applied Microbiol 32: 293-297.

Silver LL, Bostian KA 1993. Discovery and development of new antibiotics: The problem of antibiotic resistance. Antimicrob Agent Chemother 37: 377-383.

Soares MJS, Silva-Carvalho MC, Ferreira-Carvalho BT, Figueiredo AMS 2000. Spread of methicillin-resistant Staphylococcus aureus belonging to the Brazilian epidemic clone in a general hospital and emergence of heterogenous resistance to glycopeptide antibiotics among these isolates. $J$ Hosp Infect 44: 301-308.

Sousa CMM, Silva HR, Vieira Júnior GM, Ayres MCC, Costa CLS, Araújo DS, Cavalcante LCD, Barros EDS, Araújo PBM, Brandão MS, Chaves MH 2007. Fenóis totais e atividade antioxidante de cinco plantas medicinais. Quim Nova 30: 351-355.

Suffredini IB, Sader HS, Gonçalves AG, Reis AO, Gales AC, Varella AD, Younes RN 2004. Screening of antibacterial extracts from plants native to the Brazilian Amazon Rain Forest and Atlantic Forest. Braz J Med Biol Res 37: 379-384.

Tanaka JCA, Silva CC, Dias Filho BD, Nakamura CV, Carvalho JE, Foglio MA 2005. Constituintes químicos de Luehea divaricata Mart. (Tiliaceae). Quim Nova 5: 834-837.

Vieira Jr GM, Silva HR, Bittencourt TC, Chaves MH, Simone CA 2007. Terpenos e ácidos graxos de Dipteryx lacunifera Ducke. Quim Nova 30: 1658-1662.

Weniger B, Lobstein A, Um BH, Vonthron-Senechau C, Anton R, Usuga NJ, Basaran H, Lugnier C 2005. Bioactive triterpenoids from Vochysia pacifica interact with cyclic nucleotide phosphodiesterase isozyme PDE4. Phytother Res 19: 75-77. 